\title{
ARAGONESES ET BRABANÇONES. MONTAÑESES EN ARMAS Y GUERRA FEUDAL EN EL PIRINEO CATALÁN (SIGLOS XII-XIII)
}

\author{
ARAGONESES ET BRABANÇONES. \\ HIGHLANDERS IN ARMS AND FEUDAL WAR \\ IN THE CATALAN PYRENEES (12 $2^{\text {TH }}-13^{\text {TH }}$ CENTURIES)
}

Carles GASCÓN CHOPO

Universidad Nacional de Educación a Distancia carles_gascon@hotmail.com

Resumen: El presente artículo aborda la cuestión de la naturaleza y la caracterización de unos contingentes militares que, vinculados con los conflictos que enfrentaron a la nobleza feudal de los condados de Urgel y de Cerdaña contra la Iglesia de Urgel y sus aliados entre los siglos XII y XIII, se caracterizaron por la violencia y la amplitud de sus campañas de saqueo y destrucción en las tierras altas del valle del Segre, impulsando su acción la fortificación sistemática de dicho territorio.

Palabras clave: Guerra feudal, Pirineos, comunidades de montaña, paz territorial, saqueo, siglos XII y XIII.
Abstract: This article will reveal the question of the nature and characterization of some military contingents linked to the conflicts between the feudal nobility of the counties of Urgel and Cerdanya and the Church of Urgel and its allies between the $12^{\text {th }}$ and $13^{\text {th }}$ centuries. The action of those troops was characterized by the violence and the extent of their looting and destruction campaigns in the highlands of the Segre valley, promoting their action their systematic fortification.

Keywords: feudal warfare, Pyrenees, highlander communities, territorial peace, looting, $12^{\text {th }}$ and $13^{\text {th }}$ centuries. 


\section{Introducción}

El 8 de diciembre de 1198, el papa Inocencio III autorizaba a los canónigos de la catedral de Urgel a elegir un nuevo obispo en sustitución de Bernat de Castelló, el cual había presentado su renuncia tras un pontificado breve y muy turbulento. El hasta entonces obispo de Urgel no pudo presenciar — puesto que había huido de la diócesis - el incendio de la villa de la Seu d'Urgell ni el saqueo de su catedral de la mano de un contingente armado, dirigido por el conde Ramon Roger de Foix, a cuyos efectivos se refirió el papa como «aragones et brabançones» (Migne, 1855: 427-428). De un modo parecido, unos años más tarde, el monje Pierre des Vaux de Cernay se refería a este mismo episodio en su Historia Albigensium, ${ }^{1}$ caracterizando a sus autores como «multitudine ruptariorum» (Vaux de Cernay, 1615: 116).

Las etiquetas empleadas para identificar a los autores del saqueo de la catedral de Urgel remiten directamente a las actas del III Concilio de Letrán, celebrado en 1179, en el que fueron condenados los brabanzones, aragoneses, navarros, vascones, coterelos y triaverdinos, asimilándolos a los herejes a causa de los excesos cometidos al margen de las convenciones de la guerra feudal (Mansi, 1778: 232). Bajo tales denominaciones suele agruparse una tipología de combatientes de a pie, muy efectivos en los campos de batalla medievales, especialmente en el asalto y captura de fortalezas, y cuya capacidad militar suele vincularse a un contrato de carácter económico, más próximo a la guerra mercenaria que a las obligaciones feudales (Mallett, 2005: 274-275). Su violencia y efectividad, sus frecuentes agresiones contra hombres y bienes de la Iglesia y el carácter retribuido de su servicio cubrieron de oprobio a este tipo de tropas, cuya actividad fue objeto habitual de condena eclesiástica (Duby, 1996: 910-911). Los nombres que los identifican no hacen referencia tanto a unos orígenes geográficos concretos como a su condición de extranjeros - desde la perspectiva de sus víctimas - y a una posible vinculación con ciertos ámbitos rurales y de montaña, o con áreas marginales de espacios muy urbanizados, como Flandes o Brabante, indicativos de una baja extracción social y, posiblemente, de unas necesidades económicas concretas (Mallett, 2005: 275). En cuanto al concepto de «ruptiarii», derivado del latín «rumpere»,

1 La Historia Albigensium fue redactada entre 1212 y 1218 aproximadamente (Alvira, 2002: 121-123). Aun tratándose de una obra influida por un sesgo ideológico concreto, es muy cercana a los hechos ocurridos en la Seu d'Urgell a finales del siglo XII y, por supuesto, perfectamente afín al contexto ideológico y socioeconómico en el que se produjeron tales hechos. 
en su significado de romper o quebrar, sería una clara referencia a los efectos destructivos de su actividad.

Documentados con frecuencia desde mediados del siglo XII en las campañas continentales del rey Enrique II Plantagenet contra los reyes capetos (Boussard, 1946: 189-224), el empleo de estos «ruptiarii» se expandirá con rapidez por buena parte de Occidente, introduciendo nuevas formas de combate que comportarán profundas modificaciones en el arte de la guerra. El saqueo de la catedral de Urgel de finales del siglo XII, con todas las reacciones indicadas, fue la primera gran acción atribuida a este tipo de combatientes en Cataluña. Dicho episodio histórico ha llenado de perplejidad a los historiadores que se han interesado por el tema, siendo notables las dificultades para su correcta contextualitzación. En este sentido, la historiografía local, vinculada en gran medida a círculos próximos a la Iglesia de Urgel, suele identificar a los atacantes de la catedral como gentes de procedencia foránea, cuya aversión hacia la Iglesia católica, documentada en diversos memoriales de agravios, se explicaría por su supuesta vinculación con la herejía cátara. Esta línea interpretativa, tácitamente apuntada ya por Charles Baudon de Mony a finales del siglo XIX (1896, I: 115-121), y acentuada por Pere Pujol, archivero de la catedral de Urgel (Puig i Cadafalch, 1918: 53-55), ${ }^{2}$ fue retomada por Mathias Delcor, sacerdote y erudito de la Cerdaña francesa, que identificó el saqueo de la catedral de Urgel y otros episodios similares más o menos coetáneos del condado de Cerdaña, con una invasión cátara llevada a cabo desde tierras occitanas, que explicaría, incluso, el asentamiento de la herejía en la vertiente meridional de los Pirineos (Delcor, 1979-1980). Hasta tiempos muy recientes, esta ha sido la línea dominante del discurso historiográfico (Baraut, 19941995: 490-491).

En los últimos años, el episodio del saqueo de la catedral de Urgel ha sido objeto de nuevas lecturas, especialmente desde el prisma de la compleja situación política del área pirenaica de finales del siglo XII, repercutiendo en una progresiva desvinculación de sus actores con la idea de una invasión foránea vinculada con el catarismo en expansión (Gascón, 2010a). A ello ha contribuido también el análisis de otro episodio de saqueo sistemático en el condado de

2 Las reflexiones de Pere Pujol en torno al saqueo de la catedral de Urgel, así como sus efectos sobre la continuidad de las obras de la misma fueron apuntadas en la obra Santa Maria de la Seu d'Urgell, firmada por el célebre arquitecto barcelonés Josep Puig i Cadafalch, pero escrita en su mayor parte, como se ha demostrado recientemente, por Pere Pujol (Arbués y Gascón, 2017: 174-175). 
Cerdaña, protagonizado por el conde de Foix y el vizconde de Castellbò ya entrado el siglo XIII (Gascón, 2010b; Gascón, 2017), que presenta grandes similitudes con la agresión de la sede urgelense y que, en algunos de los trabajos citados en el parágrafo anterior, habían sido confundidos en un mismo episodio.

Partiendo de estas últimas premisas, proponemos volver en el presente artículo sobre la cuestión de los excesos provocados por quienes llamaremos «ruptiarii» para emplear el concepto utilizado en la época, con la voluntad de delimitar el fenómeno y de analizar la naturaleza y el papel de sus artífices en el contexto socioeconómico del Pirineo catalán. En este sentido, hemos restringido el ámbito geográfico del presente estudio al área de influencia más próxima de la sede diocesana de Urgel, que incluye las tierras altas del condado de Urgel con los valles de Andorra, y los antiguos condados de Cerdaña y Pallars, conscientes de la existencia de este mismo fenómeno en otros ámbitos del Pirineo, ${ }^{3}$ pero guiados por la necesidad de centrarnos en un espacio bien delimitado y documentado, evitando dispersiones que dificultarían la percepción del fenómeno.

\section{Saqueo, terror, destrucción}

La mayor parte de los excesos atribuidos a los «ruptiarii» en nuestro ámbito de estudio se recoge con gran detalle en tres memoriales de agravios, una tipología documental cuya naturaleza se asimila a un asentamiento contable de la violencia señorial. En ellos se incorporan las agresiones cometidas por un señor feudal con el fin de denunciarlas ante una instancia superior y de calcular el castigo y el volumen de las indemnizaciones (Bisson, 2002: 81). El más antiguo de estos documentos fue redactado con motivo de las violencias cometidas en el condado de Cerdaña, en una guerra sostenida entre el vizconde Arnau de Castellbò y el señor Arnau de Saga ${ }^{4}$ Aunque el documento no está datado, Thomas N. Bisson lo sitúa en torno a 1188 (Bisson, 1991, 99). Un

3 Entre otros episodios de característica similares y más o menos coetáneos, cabe destacar las agresiones promovidas por el conde Hugo IV de Ampurias contra la Iglesia de Girona en el contexto de la insurrección de los Montcada y sus aliados contra la monarquía en 1223. En el transcurso de dicha insurrección, el conde Hugo se sirvió de tropas que cometieron robos y destrucciones en los dominios y propiedades episcopales (Benito, 2005: 139-143).

4 Archivo de la Corona de Aragón (ACA), Extrainventario 3.465. 


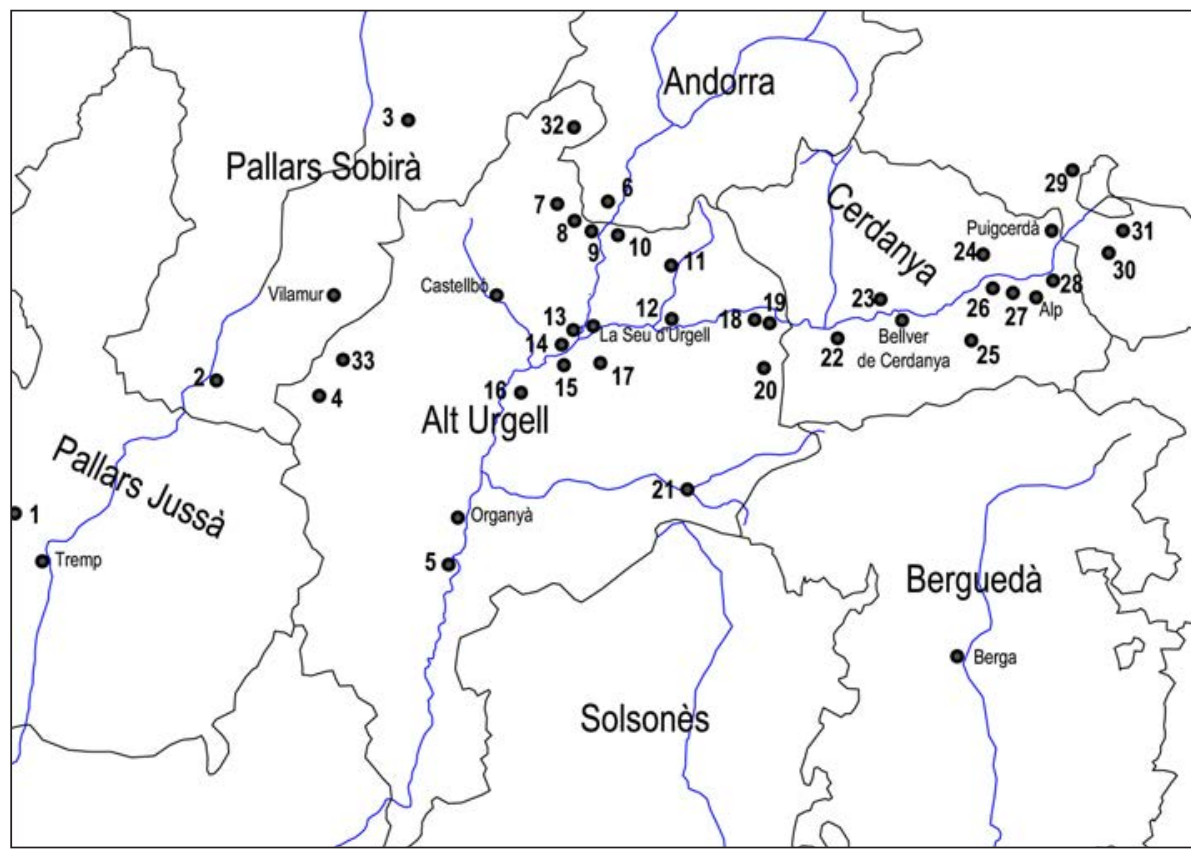

Mapa de las localizaciones de los lugares citados en el presente artículo.

1 Gurp; 2 Gerri de la Sal; 3 Tírvia; 4 Taús; 5 Coll de Nargó; 6 Tolse; 7 Asnurri; 8 Argolell; 9 La Bastida de Ponts; 10 Arcavell; 11 Bescaran; 12 Estamariv; 13 Castellciutat; 14 Montferrer; 15 Arfa; 16 Pla de Sant Tirs; 17 La Bastida d'Hortons; 18 Toloriv; 19 Bar; 20 Aragall; 21 Tuixent; 22 Montellà; 23 Prullans; 24 Ger; 25 Urús; 26 Sanavastre; 27 Mosoll; 28 Urtx; 29 Angostrina; 30 Santa Llogaia; 31 Naüja; 32 Os de Civís; 33 Guils del Cantó.

segundo memorial características similares, ${ }^{5}$ igualmente sin fecha pero datado recientemente entre 1226 y 1230 , recoge de un modo muy sistemático la campaña de saqueo llevada a cabo por tropas bajo el mando del vizconde Arnau de Castellbò y de su yerno, el conde Roger Bernat II de Foix en el condado de Cerdaña (Gascón, 2017: 79-81). El tercer documento, el más extenso de todos ellos, es copia de un original registrada en un cuadernillo de pergamino. ${ }^{6}$ Este tercer documento, redactado entre 1239 y 1241 con el fin de denunciar al conde Roger Bernat II de Foix ante el arzobispo de Tarragona (Gascón, 2017: 83), reproduce en gran medida el contenido del anterior en lo que respecta al sa-

5 Archivo Capitular de Urgel (ACU), pergaminos, Caboet-Castellbò, 33.

6 ACU, cuaderno en pergamino, pergaminos, Caboet-Castellbò, 36, f. $4^{\mathrm{r}}-8^{\mathrm{r}}$. 
queo de Cerdaña, pero incorpora otros muchos episodios de tipología similar, entre ellos el saqueo de la catedral de Urgel al que hiciera referencia el papa Inocencio III unos cuarenta años atrás, así como otra ostentosa acción militar protagonizada por el conde Roger Bernat II de Foix también en las inmediaciones de la Seu d'Urgell.

Entre otros episodios tratados con menor detalle, destaca en esta documentación el relato de cuatro campañas militares de gran alcance, caracterizadas por unos objetivos ambiciosos y un nivel singular de violencia, y que habrían implicado, aparentemente, a un gran número de combatientes. La primera campaña, datada en 1188, había tenido como escenario el condado de Cerdaña y de protagonistas a las tropas de Arnau de Castellbò — que ostentaba también la dignidad vizcondal en dicho condado--, enfrentadas con las del noble ceretano Arnau de Saga. Las quejas recogidas en el memorial hacen referencia a la violación de la paz pública implantada por el rey en las asambleas de 1173, 1187 y 1188 . Con este instrumento, que hundía sus raíces en las antiguas asambleas de Paz y Tregua del siglo anterior, el monarca pretendía ampliar las bases de su supremacía frente a los barones del territorio mediante el monopolio de la violencia. Por ello, la guerra entre los dos Arnaus dañaba a los intereses de la monarquía no solo por los ataques sufridos en las jurisdicciones reales, sino también por su desafío a las propias bases de la soberanía real. La campaña fue abundante en excesos por ambas partes, destacando sin embargo la efectividad de las tropas de Arnau de Castellbò, que atacaron no menos de 25 poblaciones, incluyendo el incendio de tierras de cultivo en las inmediaciones de Puigcerdà, la capital del condado. Numerosas cabezas de ganado mayor y menor fueron robadas por ambos bandos, y también fueron tomados rehenes para exigir rescates. El incendio de casas y propiedades, así como el derramamiento del vino de tinas y toneles, fueron expresiones propias de este episodio, dirigidas a minar las bases económicas del adversario y a sembrar el terror. Las poblaciones de Angostrina y Urtx fueron incendiadas, así como varias iglesias y dos fortalezas. Entre estas últimas, hay que mencionar la demolición del castillo de Prullans por parte de las tropas de Arnau de Castellbò, una fortaleza real cuyo sello y cuyo pendón fueron incautados en una acción de gran simbolismo contra la autoridad del rey (Bisson, 1991: 95-107).

Cronológicamente, el siguiente episodio de estas características consistió en el ataque y el saqueo de la catedral de Urgel por parte de las tropas del conde Ramon Roger de Foix. Dicho acontecimiento, que sucedió entre 1195 y 
1196, implicó la destrucción de la villa de la Seu d'Urgell y la toma de su catedral, donde habían sido sitiados los vecinos y los clérigos de la población, que habían convertido el gran templo en una fortaleza improvisada. Los atacantes sustrajeron de la catedral el oro y la plata de sus altares, paños de seda, objetos litúrgicos de metales preciosos y ornamentos y, en definitiva, todo aquello que pudiera tener un valor de venta en el mercado, capturando también a clérigos y laicos para exigir un rescate por ellos (Marquès, 2006-2008: 45). Asimismo, los agresores rompieron campanas y cometieron homicidios y otros excesos en el interior del templo (Migne, 1855: 427-428). Según todos los indicios, el ataque dirigido por el conde de Foix respondía a una operación de castigo contra los habitantes de la Seu d'Urgell y contra una parte de su colegio canonical, que estaban en desacuerdo con la elección forzada de Bernat de Castelló como nuevo obispo de Urgel en el marco de la compleja situación política urgelense de finales del siglo XII. Dulce de Foix, madre del conde Ermengol VIII de Urgel y tía de Ramon Roger, pudo haber sido la persona que impulsara la intervención de un conde de Foix que había llegado para quedarse como uno de los grandes protagonistas de la vida política del condado de Urgel a partir de entonces (Gascón, 2010a: 23-40).

La tercera campaña vuelve a tener el condado de Cerdaña por escenario. En esta ocasión, la expedición militar fue dirigida conjuntamente por el conde Roger Bernat II de Foix y su suegro, el vizconde Arnau de Castellbò, y tuvo lugar en algún momento situado entre 1223 y 1226. Los dos documentos que recogen este episodio se refieren a unas 30 iglesias atacadas, con daños en grado diverso - que en algún caso, como en Mosoll, implicó el incendio y su destrucción total-, reportando robos de bienes de sus respectivos clérigos, especialmente trigo, ganado mayor y menor, vino, aceite e incluso mobiliario de sus hogares, así como libros, ornamentos de la iglesia, indumentaria, cálices y otras piezas litúrgicas. Las agresiones fueron más allá de los templos y de los clérigos, tal como sucedió en Mosoll, donde sus vecinos, refugiados en una torre o columbario, estuvieron a punto de morir abrasados por los atacantes. Asimismo, se recogen los testimonios de diversos actos sacrílegos, como el episodio en el que los saqueadores se encaramaron aprovechando los brazos de la cruz de la iglesia de Sanavastre para alcanzar el dosel del baldaquino, o bien la preparación de comida en el interior de dicha iglesia, violaciones o la profanación de reliquias y de la Sagrada Forma. En esta ocasión, la campaña se produjo en el contexto de la guerra que enfrentó al bando nobiliario de Guillem Ramon de Montcada — del cual formaba parte el vizconde de Castellbò 
y su yerno el conde de Foix-, con Nuño Sancho, conde de Cerdaña y de Rosellón, y primo del rey Jaime I (Gascón, 2017: 84-93).

Finalmente, y en lo referente a los memoriales de agravios, la última gran campaña recogida en ellos vuelve a circunscribirse en torno a la Seu d'Urgell. Avanzada la década de 1230, y en el contexto de una violenta reactivación del tradicional conflicto que enfrentaba a la Iglesia de Urgel, en estos momentos dirigida por el enérgico obispo Ponç de Vilamur, contra el vizcondado de Castellbò, en manos del conde Roger Bernat II, viudo de Ermessenda, hija de Arnau de Castellbò, y de su hijo Roger, heredero de ambos (Baudon de Mony, 1896, I: 167-172). En 1239 Roger Bernat II y su hijo llevaron a cabo nuevos ataques contra el centro jurisdiccional de la Iglesia urgelense, matando a 26 vecinos de la villa episcopal, incendiando el núcleo cercano de Boixadera, destruyendo los castillos episcopales de Asnurri y del Pla de Sant Tirs, situados a menos de diez kilómetros a norte y sur de la sede episcopal, respectivamente, y sitiando, finalmente, la Seu d'Urgell (Marquès, 2006-2008: 52). Vinculado con este mismo conflicto, hallamos otras dos campañas de saqueo dirigidas por padre e hijo contra el condado de Pallars, donde fueron saqueados 20 templos por un valor calculado en más de 10.000 sueldos, y contra las tierras de los barones de Pinós, en el alto Berguedà, con 7 iglesias saqueadas por un valor de 500 monedas de oro (Marquès, 20062008: 51). Si en el caso del Pallars, la mención al asesinato del sacerdote de Tornafort nos sitúa en los dominios del vizconde de Vilamur, hermano del citado obispo de Urgel, en el caso del señorío de los Pinós, su titular, Galceran IV, era uno de los más fieles colaboradores del rey Jaime I en el ámbito pirenaico (Gascón, 2015: 433-434), y ello muy a menudo lo situaba entre los enemigos de los condes de Foix.

Más allá de estos memoriales de agravios, hallamos todavía otras operaciones militares de gran alcance que, por tipología y por sus efectos, podemos asimilar hasta cierto punto a las anteriores. Una de ellas, cuyo conocimiento nos ha llegado por fuentes secundarias a causa de la pérdida de la documentación original, fue impulsada por Sancha de Aragón, viuda del rey Alfonso el Casto y madre de Pedro el Católico, con quien no se llevaba muy bien. La noticia, recogida por Jaime Villanueva, contiene las quejas de un obispo de Urgel, - de quien solo consta una inicial que debería referirse a Bernat de Vilamur-, ante el arzobispo de Tarragona sobre una serie de hombres enviados en ayuda del caballero Ramon de Cervera a los que denomina aragoneses, y a quienes acusaba de haber incendiado la iglesia episcopal de Gurp, en el 
Pallars Jussà, cerca de la villa de Tremp, junto a otros daños y robos cometidos, exigiendo por ello su excomunión y la restitución de los bienes (Villanueva, 1850: 65). Este episodio debe integrarse en uno de los numerosos conflictos que enfrentó al conde Ermengol VIII de Urgel contra sus barones, en este caso Ramon de Cervera, y también Pere de Bellvís quienes, apoyados por la reina Sancha - desconocemos por qué motivo concreto, si bien en esos momentos estaba enemistada con su hijo el rey Pedro (Alvira y Smith, 20062007: 80-81) —, se enfrentaron al conde de Urgel, lanzando un ejército formado, según Diego Monfar, por cuatro mil infantes y buen número de caballeros, contra el condado en mayo de 1200 (Monfar, 1853, 426). De este modo, proponemos la identificación de los aragoneses mencionados por el obispo Bernat de Vilamur con parte de estos cuatro mil infantes referidos por Monfar, que atacaron templos de jurisdicción episcopal para perjudicar a su titular, aliado del conde agredido, en un ejercicio que recuerda en su esencia a las campañas referenciadas en parágrafos anteriores.

Un último episodio de naturaleza muy similar, pero también con algunas diferencias significativas, como veremos, se produjo en 1277, nuevamente en torno a la Seu d'Urgell y de la mano del conde de Foix. En esta ocasión, se produce un salto cronológico importante en relación al resto de los episodios expuestos. En mayo de dicho año, el conde Roger Bernat III, al mando de un enorme ejército de mil caballeros y diez mil soldados de a pie — según la relación posiblemente exagerada del obispo Pere d'Urtx-, tomó una serie de castillos en las inmediaciones de la sede episcopal, entre ellos el del Pla de Sant Tirs, sitiaron la Seu d'Urgell y amenazaron al obispo con expugnar la villa y saquear sus bienes si no se plegaba a sus exigencias. De hecho, el propio obispo y los canónigos, aterrorizados por tales amenazas, declararon nula y sin efecto cualquier concesión que pudieran realizar en perjuicio propio o de la Iglesia de Urgel bajo la coacción del conde y de sus tropas (Baraut, 2005: 312-314). El conde de Foix nuevamente dejó un rastro de castillos destruidos, clérigos maltratados - algunos colgados incluso-e iglesias profanadas, ${ }^{7} \mathrm{se}-$ gún los patrones establecidos en episodios similares de finales del siglo XII y de la primera mitad del XIII; en esta ocasión, los hechos se engloban en el último gran levantamiento de la nobleza urgelense contra el rey de la Corona de Aragón, levantamiento que culminó con la derrota definitiva de los barones en el sitio de Balaguer en 1280 (Sabaté, 2004: 222).

7 Archivo Comarcal del Alt Urgell (ACAU), colección de pergaminos, año 1277, 225 x 270 mm. 
Junto a estas campañas de mayor alcance, las relaciones de agravios reportan otros episodios similares de carácter más limitado, como el sitio del castillo de Montellà por parte del vizconde Arnau de Castellbò, sostenido con anterioridad a 1226 y que culminó con el saqueo de los habitantes de dicha población situada en los confines occidentales del condado de Cerdaña y con el incendio de la villa vecina de Aragall (Marquès, 2006-2008: 48), o los ataques llevados a cabo por los hombres de Estamariu, en el vizcondado de Castellbò, contra los núcleos cercanos de Torres y de Bescaran (Marquès, 20062008: 50). En este último caso, la acción culminó con la destrucción del castillo de Bescaran y la muerte de su señor, el caballero Bernat Guillem de Bescaran, vasallo de la Iglesia de Urgel (Marquès, 2006-2008: 48). Dicho caballero consta ya como fallecido en 1218 , lo que nos acerca a la cronología de dicho ataque. ${ }^{8}$ Asimismo, estos memoriales, especialmente los del Archivo Capitular de Urgel, están cuajados de episodios aun menores de robos de ganado, asaltos a mansos, secuestros, agresiones y extorsiones, muy próximos todos ellos a meras expresiones de bandidaje.

Tales episodios presentan, en mayor o menor grado, una serie de patrones comunes que implicaron un empleo intensivo de combatientes de a pie con una capacidad especial para capturar y destruir fortalezas, y a cuyo paso dejaron un rastro de saqueo y destrucción. En este último aspecto, cabe destacar cierta debilidad por el saqueo de templos y bienes de la Iglesia, cuya abultada presencia en las fuentes está condicionada, sin embargo, por la naturaleza eclesiástica de las mismas. Ello nos conduce al principal aspecto en común que comparten todos estos episodios: la condena explícita de sus protagonistas, bien por parte de la Iglesia, en respuesta a las profanaciones de templos, en muchos casos de forma gratuita, bien por parte de la monarquía, motivada por la amenaza que representaban ante la perturbación de la paz pública (Bisson, 2002: 39-41). Estas características comunes permiten delimitar unas modalidades de combate específicas, cuyos actores han sido identificados como exponentes de un tipo de guerra caracterizado por el empleo de combatientes a sueldo o mercenarios (Gascón: 2018,207), de acuerdo con unos procesos socioeconómicos que fueron aflorando y asentándose en Occidente a partir de mediados del siglo XII (Mallett, 2005: 274-275). Hasta qué punto responden los actores de estas destructivas campañas del Pirineo catalán entre los siglos XII y XIII al modelo general expuesto es la cuestión que pasamos a tratar a continuación. 


\section{Tras la huella de los «ruptiarii»}

La terminología empleada para designar a los responsables de los saqueos por parte de relatores externos, como el papa Inocencio III o el monje Pierre des Vaux de Cernay, responde a unos conceptos - aragoneses, brabanzones, «ruptiarii»— tipificados por una legislación conciliar de general aplicación en Occidente, y referidos a un fenómeno que recuerda a otras realidades paralelas del Occidente europeo. En cualquier caso, estos conceptos de origen externo tienen una aplicación muy limitada para el caso pirenaico, donde reciben otras denominaciones más explícitas en cuanto a su percepción por parte de sus víctimas autóctonas, tales como gentes malignas («malignorum», Alvira, 2010, II: 812), que recogemos en la autorización concedida por el rey Pedro el Católico al obispo de Urgel para construir el castillo de la villa de Montellà en 1207 como punto de control para evitar el paso de dichas gentes, o en la fundación de la villa de Vilaplana por parte del obispo de Urgel y de Bertran de Vallferosa, para defender a los campesinos dependientes de la Iglesia de Urgel en el ámbito de Tiurana («pravorum hominorum», Baraut, 1990-1991: 181). Aun siendo de un carácter más genérico, tales denominaciones indican cuál era la percepción que de ellos tuvieron las gentes autóctonas.

Pero, ¿quienes fueron estos «ruptiarii» cuya acción se consideraba tan reprobable? Por suerte, nos han llegado los nombres de algunos de los responsables de estas destrucciones que aportan algunas pistas reveladoras al respecto. El memorial de agravios referido al saqueo de Cerdaña de 1188, por ejemplo, informa que G. de Alp, aliado de Arnau de Castellbò, incendió la iglesia de Sant Andreu y mató allí a un hombre. Otro de sus valedores, R. de Urtx, incendió el núcleo de Angostrina, robando muchas cabezas de ganado (Bisson, 1991: 103). En ambos casos, los nombres de estos seguidores del vizconde de Castellbò son acompañados de sendos locativos que aluden a dos poblaciones del propio condado de Cerdaña. En otro documento similar - en este caso sin datar, aunque suponemos que escrito en torno a 1200 por su alusión a un obispo B. que debería ser Bernat de Castelló (1195-1198) o Bernat de Vilamur (1198-1203) - , son acusados diversos particulares por los excesos cometidos en el mismo condado de Cerdaña y en la Seu d'Urgell (Baraut, 1992-1993, 125). Entre otros son recogidos los nombres de Pere de Palau, a quien se acusó de haber capturado hombres de la Seu d'Urgell para pedir un rescate por ellos, y Ferrer y P. de Font, ambos identificados como hombres de Mosoll, que destruyeron las puertas de la iglesia de dicha población y la incen- 
diaron, hiriendo gravemente a los hombres que allí se encontraban. También acusó al hijo del rector de Alp como uno de los autores de la destrucción de la casa del rector de la población ceretana de Ger.

Siguiendo con el registro de los responsables de estos ataques, el obispo de Urgel señalaba a I. de Nargó y a sus compañeros como los incendiarios y destructores de la Seu d'Urgell (Marquès, 2006-2008, 45), episodio que debemos identificar con el saqueo llevado a cabo por el conde Ramon Roger de Foix hacia $1196 ;{ }^{9}$ el nombre citado atribuye al supuesto autor material de los hechos una relación con la población de Coll de Nargó, situada aguas abajo del río Segre. Por su parte, Pere y A. de Aguilar, ambos vinculados con el ya mencionado sitio del castillo de Montellà (Baraut, 2005: 274), tenían alguna relación con el castillo de Aguilar, situado en el valle del mismo nombre, muy próximo al área de influencia del vizcondado de Castellbò. En relación con el nuevo saqueo de Cerdaña, llevado a cabo poco antes de 1226 por Roger Bernat II de Foix y Arnau de Castellbò, vuelven a documentarse hombres procedentes de Urtx, concretamente R. de Capdevila y Joan Xicó; este último estuvo presente en los ataques a las iglesias de Sant Grau d'Urús, de Prats y, probablemente, de Santa Llogaia; y también figuran B. de Toloriu, — vinculado con una población homónima situada al oeste del condado, que atacó la iglesia de Sant Climent d'Urús - y Arnau de Saga, caballero de Cerdaña, ya conocido por su anterior enfrentamiento con Arnau de Castellbò en 1188 (Baraut, 2005: 290-296). Otro nombre relacionado con los saqueos llevados a cabo por parte de los Castellbò o los Foix es el de A. dels Castells, procedente del ámbito de influencia del vizcondado, próximo al valle de Aguilar, que saqueó el valle de Tost, el castillo episcopal de Montferrer, la villa de Argolell y otros lugares próximos a la Seu d'Urgell, dirigiendo a los hombres procedentes de los dominios de los condes de Foix - concretamente a los hombres de Castellbò y del valle de Aguilar,- - en sus ataques contra la Iglesia (Marquès, 2006-2008: 51).

Como puede apreciarse, buena parte de las denuncias se refieren a hombres vinculados con el ámbito de influencia del vizcondado de Castellbò y del condado de Cerdaña. Ello lo sabemos por el locativo que los identifica. Solo algunos nombres puntuales, tales como Juan de Aragón o G. Lemozin (Baraut, 1992-1993: 125), parecen pertenecer a gentes foráneas. En cualquier caso,

9 De hecho, la queja concreta expresada por el obispo fue la protección que deparó el conde de Foix al dicho I. de Nargó tras los hechos mencionados. 
estos nombres recogidos en los diversos memoriales de agravios hacen referencia a valedores, fieles o aliados de los principales señores que promovieron los ataques — vizconde de Castellbò o condes de Foix principalmente-, algunos de ellos pertenecientes, a su vez, a familias de la nobleza menor del territorio, como los Nargó, los Saga, los Aguilar o los Castells, a los que podemos añadir otros miembros de familias destacables a nivel local, como el hijo del rector de Alp. En este sentido, aunque la documentación no lo refleja de un modo explícito, estos hombres citados nominalmente pudieron ser quienes capitanearon a los destacamentos atacantes, situados bajo las órdenes de los Foix, los Castellbò u otros. Así, la destrucción de la iglesia de Santa Llogaia durante la expedición de saqueo de Cerdaña, poco antes de 1226, fue atribuida a I. de Tolse y a los hombres de Urtx por igual (Baraut, 2005: 293); esto podría ajustarse al modelo de un capitán, I. de Tolse —el locativo de cuyo apellido podría estar relacionado con el Mas de Tolse del valle de Andorra- que comandaba a sus hombres, en este caso los de Urtx. Por su parte, los ataques llevados a cabo por A. de Castells sobre las jurisdicciones eclesiásticas del valle de Tost, Montferrer y Argolell en la década de 1230 fueron realizados con el concurso de hombres de los valles de Aguilar y de Castellbò (Marquès, 2006-2008, 51), todos ellos sujetos al conde Roger Bernat II de Foix. También G. Isarn, en ese mismo período, capturó a diversos hombres de la Seu d'Urgell con el fin de obtener su rescate con el consejo y el auxilio de los hombres de los dominios del mismo conde de Foix y de su hijo (Marquès, 2006-2008: 50), seguramente de los mismos dominios pertenecientes al antiguo vizcondado de Castellbò. Finalmente, constan diversas agresiones llevadas a cabo por los hombres de Taús y también por los hombres de Coll de Nargó, — dirigidos estos últimos por el baile G. Tauler-, contra los dominios eclesiásticos de Valldarques, territorio de jurisdicción capitular situado en los confines occidentales del condado de Urgel (Marquès, 2006-2008: 52).

Hombres de Urtx, en el condado de Cerdaña, hombres de los valles de Aguilar y de Castellbò, de Taús y de Coll de Nargó, en el de Urgel, hombres de las comunidades montañesas del alto valle del Segre, dirigidos por caballeros o prohombres del territorio y, en algún caso, también por forasteros: ¿fueron estos los temibles «ruptiarii» que tanto perturbaron la paz en el Pirineo catalán a lo largo de un siglo? La documentación parece señalar, efectivamente, a los hombres de estas comunidades como los autores materiales de los ataques. De ningún modo debemos menospreciar su capacidad combativa ni su valor militar. Muy al contrario, existen buenos ejemplos de ello, como la 
destrucción del castillo de Bragafolls entre 988 y 992. Construido por el conde Borrell II de Barcelona y Urgel en la entrada de los valles de Andorra con la intención de reorganizar su patrimonio en dicho territorio, la presencia del castillo provocó la reacción violenta de las comunidades andorranas, que lo consideraron una imposición arbitraria del conde y lo destruyeron por esa razón (Viader, 2003: 75-81). De un modo similar, aunque en esta ocasión instigados por el obispo Ot de Urgel (1095-1122), los hombres del valle pallarés de Cardós se comprometieron, en un documento sin datar, a derribar el castillo de Tírvia «de capite usque in fundu», construido, al parecer, sin el consejo de dichos hombres y contra los intereses de la Iglesia (Baraut, 1988-1989: 168). Por su parte, en 1159, los hermanos Pere, Guillem y Ponç de Sant Joan, caballeros del valle homónimo situado en el flanco occidental de los valles de Andorra, convinieron con su señor, el obispo de Urgel, poner a su disposición a todos los hombres del valle, fueran caballeros o tropas de a pie («tam militibus quam peditibus»), para luchar en las campañas de dicho prelado en los condados de Pallars y de Urgel (Baraut, 1990-1991: 60).

Estos episodios, previos todos ellos a las grandes campañas de finales del siglo XII y de principios del XIII, nos hablan del potencial bélico de las comunidades de montaña, que configuraban un núcleo importante de tropas de a pie - perfectamente diferenciadas en este último caso del valle de Sant Joan de aquellos que luchaban con sus cabalgaduras - y con una capacidad singular para capturar y destruir castillos, características todas ellas que coinciden con las de nuestros «ruptiarii», con la diferencia significativa de que, al menos en los dos últimos casos, su capacidad militar estaba puesta al servicio de los obispos de Urgel. Las concordias o acuerdos establecidos entre las comunidades andorranas y la mitra urgelense en los años 1163 y 1176 nos permiten conocer un poco mejor las condiciones con las que dichas comunidades montañesas pusieron su capacidad militar al servicio de los señores feudales. ${ }^{10}$ Tomando la concordia de 1176, que en lo referente al servicio de armas reproduce casi al detalle los contenidos de la de 1163, los hombres de las comunidades de Andorra, presentes en el cierre del acuerdo, se comprometieron a hacer seguimiento contra los enemigos del obispo de Urgel, es decir, seguir a las huestes episcopales en sus expediciones contra aquellos, obligándose cada casa del valle a poner al servicio de la hueste a un hombre bien armado (Ba-

10 Para el estudio de las concordias de Andorra de 1163 y 1176 se han empleado las transcripciones de Cebrià Baraut en Baraut, 2005, 199-203 y 227-233, respectivamente. 
raut, 2005: 229). Un aspecto muy interesante de dicho acuerdo es el hecho de que los andorranos únicamente se comprometían a hacerse cargo del sustento de cada uno de estos hombres durante el primer día de la expedición; el resto del tiempo deberían mantenerse con todo lo que capturasen a los enemigos de la Iglesia. En este sentido Viader se pregunta si los hombres vinculados por dichos acuerdos se habrían limitado a cumplir con la letra de los mismos o si aprovecharían estas campañas lejos de casa para hacerse con algo de botín con el que compensar las incomodidades y los riesgos (Viader, 2003: 245). Esta última opción, sin duda, pudo haber dado lugar a los sistemáticos actos de saqueo que alimentaron el relato recogido en los memoriales de agravios.

Los distintos acuerdos adoptados en las concordias entre las comunidades andorranas y el obispo de Urgel, incluyendo la prestación de servicios militares, tuvieron un carácter más próximo al pacto y el reconocimiento mutuo de derechos y prestaciones que a una imposición señorial. En principio, ello concedía un margen de autonomía a las propias comunidades de Andorra en la decisión de prestar tales servicios, al menos en teoría. De hecho, esta idea concuerda con el episodio de la destrucción del castillo de Bragafolls contra los intereses de un conde, el de Urgel, sobre el cual recaía la soberanía de los valles andorranos nada menos. Esta situación es propia de la realidad vivida por las comunidades de dichos valles, caracterizada por la larga persistencia de unas estructuras prefeudales en un contexto socioeconómico que avanzaba hacia un modelo plenamente feudal, en el cual los vínculos de carácter privado y la opresión señorial fueron sustituyendo, en los territorios vecinos, el antiguo orden basado en el dominio público propio de época carolingia (Viader, 2003: 276-284). Existen acuerdos similares —o como mínimo que implicaban el juramento colectivo de los miembros de una comunidad local o de sus representantes hasta muy avanzado el siglo XII-, que nos permiten suponer que los andorranos no fueron los únicos que conservaban cierta capacidad de acción colectiva en la periferia de la dinámica feudal en aquel entorno (Baiges y Gascón, 2019: 75-76), aunque el peso de esta misma dinámica acabó condicionando la naturaleza de sus prestaciones militares y también sus efectos.

\section{Pervivencias antiguas y dinámicas feudales}

De modo que aquellos difamados combatientes que atemorizaron a propios y extraños en tierras del Pirineo catalán fueron, en gran medida, gentes autóctonas, surgidas de unas comunidades montañesas más o menos margi- 
nales en relación con los principales centros de poder local. Gentes movilizadas de acuerdo con unas premisas cuyos fundamentos se remontaban a la organización militar del mundo carolingio, basada en un ejército de hombres libres que debía actuar en la defensa de sus tierras y que podía ser movilizado para luchar más allá de las mismas (Reuter, 2005: 44-45; Bachrach y Bachrach, 2017: 109-111). En este sentido, la prestación del servicio de armas por parte de estas comunidades se había mantenido, por una parte, en el contexto de la autodefensa - reflejado en la destrucción del castillo condal de Bragafolls - , pero sobre todo como instrumento armado para el mantenimiento de la paz y la seguridad. La degradación del antiguo orden carolingio a lo largo del siglo X, acompañado por el incremento de la violencia de los magnates territoriales, impulsó al clero de las regiones occidentales del antiguo imperio franco a restaurar las instituciones de la paz y la justicia carolingias que ya no podían imponer los fantasmagóricos reyes de la Francia occidental. Presidido por monjes y prelados, este movimiento, que revalorizaba las virtudes de la paz como valor supremo en la articulación social, recuperó y actualizó las decaídas asambleas de época carolingia y contempló la movilización de los laicos asociados a los prelados para garantizar su aplicación (Bisson, 2002: 103-106).

Esta movilización de laicos a favor de la paz es documentada en situaciones y momentos diversos dentro de nuestro ámbito de estudio. La primera ocasión la hallamos en 1076, cuando los hombres de las villas de Bar y Toloriu, en el extremo occidental del condado de Cerdaña, cerraban un convenio con el conde Ermengol IV de Urgel. Sintiéndose perjudicados por los efectos del conflicto entre dicho conde y el de Cerdaña, reclamaron la protección del primero en nombre de la paz del conde y del obispo de Urgel, ofreciéndose a cambio a construir un puente sobre el río Segre a la altura de Bar (Gonzalvo, 1995: 74). Otras movilizaciones comunitarias generaron acciones más explícitas desde el punto de vista militar, como en el caso de la destrucción del castillo de Tírvia por parte de los hombres del valle de Cardós, inspirados por el obispo Ot de Urgel en un momento indeterminado entre 1095 y 1122, según ya se ha explicado (Baraut, 1988-1989: 168). A medio plazo, a partir de un momento avanzado del siglo XII, la propia monarquía se aprovechó del potencial de esta fuerza de combate comunitaria como factor de contención de la violencia señorial en aplicación de su programa específico de monopolio de la paz pública en los ámbitos de su jurisdicción, como el condado de Cerdaña (Gonzalvo, 1994: XXIV-XXVI). 
En cambio, a partir de finales del siglo XII, la monarquía y las élites eclesiásticas defensoras de un orden público ya no valoraban la acción de los hombres de las comunidades montañesas por sus esfuerzos en el mantenimiento de la paz, sino que la condenaban por sus intervenciones destructivas, atribuidas a la sed de saqueo y a un carácter intrínsecamente maligno. Este cambio profundo en la consideración de estos combatientes implica una clara discontinuidad en relación con la realidad de principios del mismo siglo, coincidiendo esta cesura con el auge de las tensiones bélicas en las tierras altas del condado de Urgel.

En 1159 Arnau de Caboet, titular de uno de los más poderosos señoríos urgelenses — que incluía el valle de Cabó y el valle de Sant Joan, así como el valle de Andorra en calidad de feudatario del obispo de Urgel—, encabezaba una insurrección nobiliaria contra el obispo Bernat Sanç. Si Arnau de Caboet pretendía deshacerse de los vínculos de vasallaje impuestos por su difunto hermano con respecto a la Iglesia de Urgel, la implicación de un nutrido elenco de nobles que le apoyaron, algunos de la talla de los vizcondes de Castellbò y de Vilamur, se ha interpretado como un intento de hacer frente a las pretensiones hegemónicas de sus prelados en el área pirenaica (Viader, 2003, 119120). Esta coalición fue vencida de manera fulminante por las tropas del obispo de Urgel, integradas en parte por los hombres del valle de Sant Joan, como ya se ha explicado, de acuerdo con el compromiso alcanzado con los caballeros Pere, Guillem y Ponç de Sant Joan que debió responder, en cierta medida, a una movilización para la preservación de la paz.

Sin embargo, la insurrección baronial de 1159, más allá de esta supuesta lucha contra la hegemonía eclesiástica, parece ser el síntoma de una problemática más profunda. Algunos nobles, comenzando por el conde de Urgel, atravesaban ciertas estrecheces económicas. De este modo, el obispo y los canónigos urgelenses prestaron en 1160 a dicho conde un cáliz de oro y piedras preciosas y un vaso de plata (Baraut, 1990-1991: 71) que, según reconoció en su testamento de 1167, se vio obligado a aceptar para atender sus grandes necesidades económicas (Baraut, 1990-1991: 144). Thomas N. Bisson propone que, tras las conquistas de Lleida y Tortosa a mediados del siglo XII, las viejas élites militares del territorio catalán debieron dejar de prosperar y se quedaron sin unas expectativas claras (2002, 37 y 100). En el caso del condado de Urgel, además, la conquista de Lleida de 1149 significó la desaparición de su antigua frontera frente al mundo musulmán, con la correspondiente pérdida de las posibilidades económicas de los miembros de los estamentos supe- 
riores de la sociedad urgelense. Todo ello redundó en un perceptible aumento de la conflictividad, no solo en los distritos pirenaicos del condado, como hemos expuesto, sino también en las áreas meridionales del mismo, con los primeros síntomas del largo conflicto que enfrentó a los condes de Urgel con los vizcondes de la casa de Cabrera (Miret i Sans, 1900: 99-100).

Asimismo, grandes instituciones eclesiásticas, como el cabildo catedralicio de Urgel, presentan una tendencia a recortar el gasto, lo que pudo repercutir sobre las economías de aquellos que se beneficiaban o que dependían del dispendio de los canónigos. ${ }^{11}$ Además de los recortes presupuestarios, las dificultades económicas que seguramente experimentó la Iglesia de Urgel en aquellos momentos incentivó la búsqueda de nuevos mecanismos para incrementar su recaudación. En este sentido, la concordia de 1163 con los andorranos es, por encima de todo y más allá de un acuerdo para el uso de su fuerza militar, un convenio para sistematizar los ingresos de antiguos derechos y censos que habían correspondido a los condes de Urgel antes de cederlos al obispo en 1133, y también para ampliar su capacidad impositiva sobre las rentas de las parroquias andorranas, invocando los postulados de la reforma gregoriana y provocando un conflicto que vino a cerrarse momentáneamente con dicho acuerdo (Baraut, 2005: 199-203).

La proliferación de este tipo de conflictos entre la Iglesia de Urgel y las comunidades de montaña parece un reflejo de la sistematización de las presiones ejercidas por la Iglesia de Urgel sobre las rentas de aquellas. En 1158 los hombres de la parroquia de Guils, en los límites del condado de Urgel con el de Pallars Sobirà, profanaron la iglesia parroquial con el concurso de sus señores, el vizconde de Castellbò y A. de Castells, y debieron comprar su perdón renunciando a los derechos consuetudinarios sobre los diezmos a favor de la Iglesia de Urgel (Baraut, 1990-1991: 52-53). En 1163 diversos parroquianos de la diócesis de Urgel, llevados por un «diabolico furore», en palabras del papa Alejandro III, invadieron las tierras de la abadía de Santa Maria de Gerri, en el condado de Pallars Sobirà (Baraut, 1990-1991: 100-101). En fin, siguiendo con la misma dinámica, en 1178, los parroquianos de Os de Civís, en

11 De este modo, el obispo Bernat Sanç aconsejaba la reducción, en 1161-1162, del número de prepósitos del capítulo de Urgel de doce a once, siendo aceptado por los canónigos, del mismo modo que acordaron poner freno al incremento del número de canónigos sin la autorización de los prepósitos (Baraut, 1990-1991, 78-80). Por su parte, su sucesor Bernat Roger, conjuntamente con los canónigos de la catedral, acordó reducir a cuarenta y cinco el número de canónigos con el fin de evitar la disminución de sus bienes, que se consideraba una amenaza inminente en el año 1163 (Baraut, 1990-1991: 106-107). 
las inmediaciones del valle de Andorra, renunciaron también a la recaudación de los diezmos y de otras rentas que tradicionalmente habían gestionado a favor de la Iglesia de Urgel, tras un largo conflicto con el obispo Arnau de Preixens (Baraut, 1990-1991: 256-257).

La ofensiva episcopal sobre unas rentas gestionadas tradicionalmente por las comunidades montañesas (Viader, 2003: 292-297), cuyos miembros habían luchado en respuesta a los llamamientos de la Iglesia de Urgel, no pudo dejar indiferentes a unos hombres acostumbrados a vivir con pocas injerencias externas en la gestión de sus asuntos cotidianos. Por ello, no es de extrañar que las mejoras de la capacidad impositiva de la Iglesia en estas tierras se acompañaran de una creciente hostilidad hacia la jerarquía episcopal y los sectores más poderosos de la Iglesia, cuyos intereses cada vez estaban más próximos a los de la nobleza laica. Hay que vincular dicha hostilidad creciente con las profanaciones de templos y los actos sacrílegos que recogen las fuentes a propósito de los «ruptiarii», pero también hay que tener en cuenta que, con sus ornamentos litúrgicos, cálices, retablos y otros objetos preciosos depositados en sus altares, los templos atesoraron verdaderas fortunas que estaban al alcance de unos agresores que, por otra parte, tenían regulado el saqueo en territorio enemigo. Y no solo estamos hablando de los templos mayores como la catedral de Urgel, donde el conde de Foix y sus hombres no dejaron nada excepto las paredes desnudas, según expresó Pierre des Vaux de Cernay (1615: 116), sino también de templos mucho más modestos, como la iglesia de Sanavastre, en la Cerdaña, donde los atacantes se apoderaron de un caldero que fue vendido posteriormente al rector de la parroquia de Estamariu por treinta sueldos (Marquès, 2006-2008: 46).

Pero más allá del saqueo de los bienes de la Iglesia, ciertamente tentador si se conseguían dejar a un lado los escrúpulos, el creciente malestar hacia ciertos sectores del clero supuso el resquebrajamiento de la confianza mutua que perjudicó las líneas de colaboración establecidas en épocas anteriores. Además, en un contexto tan conflictivo como el urgelense, con varios bandos enfrentados entre sí, los hombres de las comunidades montañesas tuvieron que elegir entre varias fidelidades posibles, quizás todas ellas legítimas desde el punto de vista de la colaboración para el mantenimiento del ordenamiento jurídico vigente, sobre todo a partir de la caída progresiva del prestigio de la institución eclesiástica.

De este modo, en 1171 el obispo Arnau de Preixens acusó al vizconde Ramon II de Castellbò, entre otras muchas cuestiones, de haberse conjurado con 
los hombres de Andorra contra los intereses episcopales. En consecuencia, los andorranos dejaron de pagar los censos y las prestaciones debidas al obispo de Urgel según lo estipulado en la concordia de 1163 (Baraut, 2005: 221). Con esta conjura, los andorranos pronunciaban un juramento alternativo que rivalizaba con el prestado anteriormente a su señor, el obispo de Urgel, amenazando con establecer fidelidades alternativas, y fue necesario hacer una nueva concordia, la de 1176, para corregir esta situación (Baraut, 2005: 228-233). Aunque no hay constancia explícita que la conjura de los andorranos incluyera la prestación de un servicio armado a favor del vizconde de Castellbò, la concordia de 1176 insiste en incluir el servicio militar entre las prestaciones debidas al obispo de Urgel. De hecho, en 1162, el obispo Bernat Sanç y los canónigos urgelenses habían puesto en manos del vizconde Ramon la encomienda del castillo de Montferrer con sus caballeros, los cuales, desde tiempo atrás, tenían la responsabilidad de la dirección militar de los hombres de Andorra (Gascón, 2019: 76). Estos precedentes dieron al vizconde de Castellbò cierta base legal para exigir el servicio de armas a los andorranos, servicio que aprovechó en beneficio de sus intereses particulares y contra los del obispo y la Iglesia de Urgel.

A largo plazo, la cuestión del aprovechamiento del servicio militar de los andorranos se convirtió en uno de los grandes argumentos que presidiría el enfrentamiento entre la Iglesia de Urgel y los vizcondes de Castellbò, y más adelante los condes de Foix, en torno a los valles de Andorra. Arnau de Castellbò, el hijo de Ramon II, atacó a los hombres de dichos valles en un momento anterior a 1226, para castigar a sus habitantes por su ayuda militar prestada al obispo contra los intereses vizcondales (Marquès, 2006-2008, 49). Esta cuestión acabó incluyéndose en los aspectos regulados en el reparto de la soberanía entre ambas partes que fue el pariaje de Andorra de 1278 (Baiges y Gascón, 2019: 148).

En cualquier caso, la conjura de 1171 nos sitúa en un contexto de fidelidades cambiantes en lo que respecta a la prestación, no ya de un servicio destinado al bien común, como lo fue el mantenimiento de la paz, sino de un servicio a favor de los intereses particulares de los señores y de los bandos enfrentados. Incluso los intereses de la Iglesia de Urgel se alejaban ostensiblemente del bien común y se aproximaron a los del resto de los señores feudales, según se percibe en la destrucción de los castillos de Montferrer, en 1188, y de Castellciutat, en 1190, por parte de las tropas episcopales (Gascón, 2018: 212 213). En este sentido, las condenas a la participación de los montañeses en las 
guerras feudales a partir de finales del siglo XII responden, básicamente, a la elección de un bando, recibiendo la condena del bando opuesto. Evidentemente, el saqueo de templos y las agresiones a los hombres de la Iglesia aportaban argumentos en las condenas emitidas por la Iglesia - la mayoría de las que nos han llegado - pero, en esencia, lo que se condenó fue la privatización de un servicio hasta entonces destinado a la salvaguardia del bien común.

\section{Efectos de una movilización permanente}

El impacto social y económico de la acción de estas bandas armadas de hombres de montaña, se produjo en la medida de su movilización sistemática en un espacio sacudido por un estado de guerra casi permanente a lo largo de varias décadas. La mayor parte de las condenas emitidas por la Iglesia de Urgel ante las acciones de dichos hombres estuvieron relacionadas con episodios promovidos y sostenidos por los vizcondes de Castellbò y los condes de Foix, sus sucesores en el gobierno del vizcondado a partir del matrimonio de los respectivos herederos hacia 1209 (Baudon de Mony, 1896, I: 135). Tras unos inicios vinculados con el levantamiento de Arnau de Caboet contra la Iglesia de Urgel en 1159, la neutralización del mismo situó a los vizcondes de Castellbò como principales referentes de la nobleza de las tierras altas de Urgel frente a los intereses de la Iglesia, en un contexto caracterizado por el recorte sostenido de la capacidad jurisdiccional de los condes de Urgel sobre los espacios originarios de su condado (Sabaté, 1995: 32). Y todo ello en paralelo a la ampliación de los dominios del vizcondado de Castellbò a raíz del matrimonio entre Arnau de Castellbò y Arnaua de Caboet en 1185 (Miret i Sans, 1900: 143-144). La crisis y el vacío del poder condal tras la muerte de Ermengol VIII en 1209 estimuló la intervención directa de otros poderes externos, el conde Ramon Roger de Foix por un lado, — que ya había intervenido en la política urgelense con el ataque a la Seu d'Urgell y el saqueo de la catedral en torno a 1196, y cuyo primogénito Roger Bernat se casará con la heredera de Castellbò hacia 1209-, y la monarquía por el otro, desde sus dominios del vecino condado de Cerdaña, aliada generalmente de la Iglesia de Urgel y enfrentada a los grandes barones. La interacción de los Foix y los monarcas en las guerras intestinas del alto condado de Urgel fueron determinantes en el rumbo tomado por los acontecimientos y en el enquistamiento de un estado de guerra que, a grandes rasgos, permaneció con sus treguas y sus reactivaciones hasta el último cuarto del siglo XIII (Baiges y Gascón, 2019: 142-154). 
El conflicto persistente, proyectado también sobre el condado de Cerdaña de la mano de los intereses de los agentes enfrentados, implicó una frecuente movilización de los «ruptiarii», cuya reconocida competencia militar tuvo como efecto principal la fortificación sistemática del territorio a través de la construcción o la reconstrucción de castillos y núcleos fortificados, algunos de ellos tan significativos como las villas nuevas de la Seu d'Urgell y de Organyà, reconfiguradas en clave defensiva durante el primer tercio del siglo XIII, o la nueva villa de Bellver de Cerdanya, documentada a partir de 1225. Tan numerosas fueron las nuevas fortalezas construidas bajo estos parámetros, que en 1233 el conde Roger Bernat II de Foix y el conde Nuño Sancho de Rosellón y Cerdaña se vieron obligados a regularizarlas mediante un acuerdo que afectaba a los castillos construidos en el transcurso de las guerras que los habían enfrentado, acordándose el derrocamiento de algunos de ellos. Otras fortalezas relevantes como los castillos de Arfa, el Pla de Sant Tirs, Tuixent, Arcavell, Fórnols o la Bastida d'Hortons, todos ellos situados en torno al núcleo episcopal de la Seu d'Urgell, fueron erigidos entre finales del siglo XII y a lo largo de la primera mitad del XIII. Esta situación contribuyó a un incremento de la presión señorial sobre los distritos pirenaicos del antiguo condado de Urgel. Por un lado, la Iglesia de Urgel se benefició de la cesión de antiguos dominios condales en los que construyó sus nuevas fortalezas, mientras que los condes de Foix, amparados por una confianza renovada en sus propias fuerzas, cuestionaban y desatendían el vasallaje debido por sus predecesores, los señores de Caboet, a la Iglesia de Urgel, ${ }^{12}$ contribuyendo con ello a la plena consolidación del conglomerado territorial que orbitaba en torno al núcleo vizcondal del valle de Castellbò. Con ello, los territorios del alto condado de Urgel quedaron articulados en dos grandes señoríos, los dominios de la Iglesia y los del vizcondado de Castellbò, uno frente a otro, fijando su organización jurisdiccional hasta prácticamente el final del Antiguo Régimen (Gascón, 2018: 232-236).

12 En principio, desde los tiempos de Arnau de Caboet (m. 1170), los valles de Caboet y de Sant Joan, dominios patrimoniales de su linaje, estuvieron sometidos al homenaje prestado por sus titulares al obispo de Urgel. Todos los sucesores de Arnau de Caboet, de un modo más o menos espontáneo, prestaron homenaje por ellos a medida que sucedían a sus predecesores, hasta el conde Roger Bernat III (1265-1302), que se negó a hacerlo, según se relata en el convenio de 1278 entre conde y obispo, conocido como 'primer pariaje de Andorra'. En dicho acuerdo se eximía a Roger Bernat III de prestar juramento de homenaje por dichos dominios de Cabó y Sant Joan al obispo y retomarlo en la figura de sus sucesores (Baraut, 2005: 121) si bien, en la práctica, este homenaje acabó cayendo en desuso incluso en Andorra a partir del siglo XIV. 
De manera más inmediata, los destructivos ataques de los «ruptiarii», marcados por su carácter depredador, provocaron graves alteraciones que afectaron de forma desigual a determinados agentes del área pirenaica, bien fuera la Iglesia de Urgel - que se vio obligada a interrumpir la construcción de la catedral tras el saqueo del conde de Foix (Puig i Cadafalch, 1918: 53-55), o que vio gravemente comprometida su capacidad crediticia ${ }^{13}$ al serle sustraída buena parte de los bienes que sustentaban su liquidez-, o los sectores más humildes del clero, como en el caso de buena parte de los curas del condado de Cerdaña que, robados, expoliados y agredidos, se vieron obligados a abandonar sus parroquias tras el ataque combinado del vizconde de Castellbò y del conde de Foix poco antes de 1226 (Baraut, 2005: 290-293). Estas realidades repercutieron en una mayor inestabilidad que alimentaba, a su vez, el discurso de la violencia. Seguramente la presencia de un clérigo robando a los hombres de Naüja junto a otros atacantes en una de las campañas sobre el condado de Cerdaña, o la del hijo del cura de Alp, también en la Cerdaña, participando en el incendio de la casa del cura de Ger (Baraut, 1992-1993: 125) respondieron a situaciones personales de ruina y desarraigo que tuvieron una repercusión más amplia de lo que nos sugiere la documentación.

\section{El desvanecimiento de los montañeses}

En 1237 el conde Roger Bernat II de Foix y el conde Nuño Sancho de Rosellón y Cerdaña pactaron el final de unas hostilidades heredadas de los últimos tiempos de Arnau de Castellbò (Baudon de Mony, 1896, I, 164-166). Poco tiempo después, en 1240, se alcanzaba también una tregua en tierras urgelenses, siendo el conde de Foix absuelto de sus pecados por el obispo Ponç de Vilamur. El conde murió al año siguiente (Baudon de Mony, I: 168-173). Ambos acontecimientos marcaron el final de un largo ciclo de enfrentamientos armados y, aunque el conflicto con la Iglesia de Urgel, se mantuvo siempre latente, el nuevo conde Roger IV de Foix le supo imprimir un carácter distinto, sustituyendo los campos de batalla por los tribunales en su acoso sistemático al obispo Ponç de Vilamur, que fue depuesto por la curia romana en 1254 (Li-

13 En torno a 1207, el nivel de endeudamiento del obispo de Urgel era tan elevado, que tanto el rey Pedro el Católico como el conde Ermengol VIII de Urgel debían garantizar la integridad de los bienes del cabildo catedralicio frente a las exigencias de los acreedores del obispo (Marquès, 2015-2018: 258 y 263). 
nehan, 1972-1973: 166-167). Este cambio de estrategia no significó en ningún caso la pacificación de los condados de Urgel y Cerdaña, pero la falta de documentación de largas campañas sangrientas, al estilo de las de tiempos de su padre y de su abuelo materno, sugieren una reducción sensible de su intensidad, quizá motivada por el agotamiento de los contendientes.

En este sentido, la presencia de gentes procedentes de dichos condados, luchando al lado de los defensores del castillo de Montsegur, último reducto de la Iglesia cátara occitana, durante el sitio sostenido por las tropas reales francesas en 1244, pudo ser sintomático de cierta desmovilización en la vertiente opuesta. Entre los catalanes que participaron en la defensa de Montsegur hallamos a Guillem Llorenç de Castellbò, que formó parte, asimismo, de una expedición que culminó con la matanza de los inquisidores de Avinhonet en 1242, y que implicó el inicio de la fase más dura del sitio de la fortaleza (Duvernoy, 1998: 135 y 145). En relación con dicho Guillem Llorenç, la documentación recoge la presencia también de un caballero llamado Bertran d'Aguilar, que también participó en la masacre de Avinhonet (Duvernoy, 1998: 85), y que podría estar relacionado, a su vez, con los caballeros de Aguilar presentes en el sitio sostenido por Arnau de Castellbò en Montellà. Otro combatiente catalán presente en Montsegur fue Ponç de Narbona, del valle de Querol, en la alta Cerdaña (Duvernoy, 1998: 42 y 159), que llegó a Montsegur con sus hermanos. Uno de ellos, Arnau, fue herido durante el sitio y se convirtió al catarismo poco antes de morir (Duvernoy, 1998: 18).

Junto a estas presencias de combatientes de origen catalán, cabe destacar el desarrollo de una operación fallida organizada por dos señores del Donasà, al norte del condado de Cerdaña, por la que pagaron a un mercenario catalán llamado Corberó para acudir en defensa de Montsegur junto con veinticinco soldados a sueldo que no lograron burlar el sitio de los franceses (Duvernoy, 1998: 147). Retomando el argumento de una posible desmovilización en la vertiente meridional de la cordillera pirenaica, este episodio pone en evidencia la cuestión de una hipotética reconversión, ahora sí, de algunos de los combatientes veteranos, desmovilizados tras un largo período bélico, en verdaderos mercenarios a sueldo.

Otro aspecto de interés vinculado a la presencia de estos combatientes de origen catalán en la defensa del castillo de Montsegur se centra en su relación con la Iglesia cátara, a cuya jerarquía defendían. Descartada la hipótesis de Mathias Delcor, que identificaba a los «ruptiarii» con invasores cátaros, la relación entre estos y la herejía se produjo en un sentido inverso: el anticleri- 
calismo latente de las comunidades montañesas, causante de cierta desafección hacia la causa de la Iglesia de Urgel, según se ha explicado más arriba, pudo haber dirigido las miradas de algunos de sus miembros hacia el movimiento cátaro, cuyos predicadores itinerantes se erigieron en representantes de una Iglesia alternativa que deslegitimaba y repudiaba a la jerarquía católica. En este sentido, la protección dispensada a estos predicadores por nobles como los Castellbò podría interpretarse como la voluntad de cohesionar su causa a través del anticlericalismo militante intrínseco en las doctrinas cátaras. En 1237, el refugio que tenían los cátaros en la villa vizcondal de Castellbò fue asaltado en una acción que permitió a los inquisidores acceder a ella, acompañados por una parte sustancial del episcopado catalán y protegidos por las tropas del vizconde de Cardona, cuya presencia en Castellbò tuvo que ser autorizada por el conde de Foix. En dicha acción fueron capturados 45 sospechosos de herejía y otros 15 huyeron (Gascón, 2015: 481-484). Es posible que alguno de estos huidos coincidiese en Montsegur con otros exiliados por la acción inquisitorial en Cataluña.

Volviendo al relato de las grandes campañas militares en las tierras altas del condado de Urgel y de Cerdaña, hay que esperar hasta 1277 para documentar un nuevo ataque de gran alcance, protagonizado por un nuevo conde de Foix, en esta ocasión Roger Bernat III, hijo de Roger IV. Nuevamente la Seu d'Urgell fue sitiada, aunque en esta ocasión no hay constancia que los atacantes consiguieran atravesar su recinto amurallado y saquear la población (Baraut, 2005: 312-314). Aunque ya se ha hecho notar una posible exageración de los cálculos expresados por el obispo de Urgel en cuanto al número de atacantes, la magnitud de la operación y la actitud de la aterrorizada jerarquía urgelense -incluyendo las supuestas exageraciones motivadas por el propio terror y por la emergencia de las circunstancias-, nos sitúan ante un ataque con ciertas características diferenciadas con respecto a las operaciones anteriores a 1240, tanto por el número como por la procedencia de los atacantes. En este último sentido, en las protestas dirigidas al papa Nicolás III, el obispo Pere d'Urtx identificaba las tropas atacantes como occitanas y tolosanas, sin mencionar en esta ocasión a gentes llegadas de un entorno inmediato. ${ }^{14}$

Todo ello, junto al paréntesis de más de treinta años sin documentar ningún ataque de estas dimensiones, marca un notable cambio de tendencia en el reclutamiento de los ejércitos que iban a hacer la guerra en los distritos catalanes de 
la vertiente meridional de los Pirineos. Habiendo desaparecido de la documentación, las huestes de las comunidades de montaña parecen haberse apartado de la primera línea de combate, siendo sustituidas por soldados y caballeros reclutados más allá de los valles pirenaicos, en el vecino reino de Francia. Aunque pudo haber influido, esta discontinuidad no puede explicarse únicamente por la atenuación de las hostilidades en torno a 1240 y a los cambios de estrategia del conde Roger IV en su lucha contra la Iglesia de Urgel. Avanzando un paso más allá en la posible explicación de estas transformaciones, los profundos cambios experimentados en el seno de las comunidades montañesas durante este prolongado período bélico - con una caída progresiva en las redes del dominio señorial favorecida por los propios desórdenes que los mismos señores habían provocado con sus guerras - , pudieron tener parte de la responsabilidad.

Uno de los principales efectos del ciclo bélico anterior a 1240 fue la fortificación sistemática del alto valle del Segre. Este proceso, pese a que pueda parecer contradictorio con las habilidades de las tropas montañesas en el asalto y la captura de fortalezas, comprometió seriamente sus capacidades ante la creación de una verdadera red castral. La proliferación de nuevos castillos por todo el territorio, así como una sensible mejoría en sus técnicas constructivas, ${ }^{15}$ procuraba una protección más eficaz a los pobladores contra incursiones y saqueos. Prueba de ello es el caso de la Seu d'Urgell, población que, una vez amurallada, consiguió rechazar los ataques de los condes de Foix de 1239 y 1277 , contrariamente a lo sucedido en el saqueo de 1196, antes de la erección de sus murallas. Asimismo, en ciertos sectores, la nueva red castral fue pensada en clave territorial, protegiendo los grandes núcleos y las vías principales, tal como sucede con la construcción del castillo de Montellà en 1207, concebido para proteger los accesos al condado de Cerdaña desde tierras urgelenses (Alvira, 2010, II: 812), o el de Arfa, erigido en torno a 1202 con el objetivo de proteger la vía de acceso a la Seu d'Urgell menos expuesta ante las tropas de Castellbò (Gascón, 2018: 225-226). Esta relativa planificación también pudo jugar su papel dificultando la movilidad de los «ruptiarii» y facilitando el apoyo mutuo de los diferentes recintos fortificados para hacerles frente de un modo más eficaz.

15 Una de estas mejoras consistió en el uso sistemático de la piedra como material constructivo frente a la madera. En este sentido, todavía en 1209 los habitantes de Aristot, en el sector occidental del antigo condado de Cerdaña, construyeron un castillo de piedra y madera que fue desmantelado por orden del vizconde Arnau de Castellbò; Bibliothèque Nationale de France (BNF), Manuscrits, col. Doat, núm. 169 , f. $145^{\mathrm{r}}-146^{\mathrm{r}}$ - 
Pero junto a su función defensiva, la proliferación de castillos favoreció también el desarrollo de nuevas formas de sujeción y de subordinación de las comunidades a la autoridad señorial. En el caso del nuevo castillo de Montferrer, erigido en torno a 1188, sus habitantes tuvieron que hacer frente a los intentos de imposición de nuevas prestaciones arbitrarias para el mantenimiento y la vigilancia de la fortaleza y de los malos usos de la «cugúcia», la «intèstia» y la «eixorquia» (Gascón, 2018: 211-214). Por su parte, con la construcción del castillo de la Bastida de Ponts, poco antes de 1241, en los límites meridionales de Andorra, el conde Roger Bernat II controló las entradas y las salidas del valle, así como la tributación sobre su comercio, que fue un modo de exigir su sumisión (Baiges y Gascón, 2019: 137-138). Estas formas coercitivas tuvieron también una expresión más explícita mediante las imposiciones arbitrarias sobre los andorranos o la prohibición a sus hombres de hacer seguimiento a las huestes episcopales, del mismo modo que ya había sido prohibido a los hombres de los valles de Cabó y de Sant Joan (Marquès, 2006-2008: 49-50). En lo referente a las comunidades andorranas, el pariaje de 1278, que ponía las bases de la soberanía compartida del obispo de Urgel y el conde de Foix sobre las mismas, nos da la justa medida de hasta qué punto habían caído esas comunidades bajo la dependencia señorial en lo relativo al servicio de armas, al acordar ambos señores, prescindiendo de la opinión de los andorranos, el libre empleo de su hueste siempre que no fuese para atacar al otro señor (Baraut, 2005: 321). En estas alturas, la diferencia con el margen de maniobra que se atribuyeron los andorranos en las concordias de 1163 y 1176 es abrumador. El acuerdo de 1278 sobre el empleo de las huestes de Andorra ya no fue un pacto o un reconocimiento mutuo de derechos y prestaciones entre el señor y las propias comunidades, como en el caso de las concordias, sino una imposición al más puro estilo feudal.

La progresiva pérdida de autonomía de las comunidades montañesas, ejemplificada por el caso bien documentado y estudiado de Andorra, implicaba una mayor capacidad coercitiva por parte de unos señores que ya habían sometido a buena parte de las comunidades montañesas involucradas anteriormente en los asaltos y los saqueos que acompañaron las campañas descritas. A un nivel más general, la antigua prerrogativa del servicio de armas había ido sustituyéndose, allí donde el poder señorial aparecía firmemente asentado, por prestaciones censuales o monetarias, limitándose la intervención directa del campesinado a episodios bélicos de carácter excepcional (Sabaté, 2007: 9899). El condado de Cerdaña, de jurisdicción real, ya había comenzado a cami- 
nar para encontrar fórmulas de pacificación del territorio desde finales del siglo XII, con la erección de la villa real — y fortificada - de Puigcerdà hacia 1178 (Rovira, 2005: 199-204), y la creación de la nueva figura del «veguer» de Cerdaña, que debía de garantizar el mantenimiento de la paz pública mediante el mando de las milicias campesinas y urbanas para perseguir a sus violadores (Bisson, 2002: 103). Aunque todo ello no bastó, ni de lejos, para contener la acción de los «ruptiarii» en la Cerdaña, sí que hallamos documentada la movilización de las milicias urbanas de Puigcerdà, los «homines Podii Cerdani», impidiendo el incendio del columbario del lugar de Mosoll, donde se habían refugiado sus habitantes en la campaña que tuvo lugar poco antes de 1226 (Marquès, 2006-2008: 46).

Con la nueva figura de los «veguers», la monarquía asentó las bases para reorientar la prestación del servicio de armas de las comunidades montañesas en beneficio propio y de su particular noción del dominio público. El rey también llegó a intervenir en tierras urgelenses, tal como hizo Pedro el Grande en 1278, cuando sitió al conde de Foix y a sus tropas en Castellciutat, una fortaleza inmediata a la Seu d'Urgell, exigiendo a los andorranos el abastecimiento de sus tropas con pan, vino, carne y cebada y amenazando con entrar por la fuerza a su valle si se negaban (Baiges y Gascón, 2019: 141 y 146-147). Estas amenazas a las comunidades locales por parte de grandes contingentes de tropas foráneas - las del conde de Foix en 1277 y las de Pedro el Grande en 1278 - fue otro factor de importancia por su contribución a neutralizar la capacidad y la voluntad de combate de dichas comunidades, coaccionadas por la presencia de contingentes mucho mayores, como ya se había producido en Castellbò en 1237 a raíz de la intervención inquisitorial. Esta presencia cada vez más frecuente de fuerzas externas responde a la progresiva integración de los territorios afectados en esferas de acción política cada vez más amplias y eficaces, como lo era la Corona de Aragón, cuyos titulares obtuvieron la plena legitimidad como señores eminentes de los antiguos condados pirenaicos a raíz del tratado de Corbeil en 1258, o la autoridad pontificia que, mediante el perfeccionamiento de sus instrumentos burocráticos y la ampliación de su capacidad jurisdiccional a ámbitos cada vez más amplios de la sociedad, obtuvo los mecanismos necesarios, como el Tribunal de la Santa Inquisición, para controlar a sus fieles de un modo mucho más efectivo. La capacidad coercitiva que conllevó esta combinación de mayor presión señorial y mejor control externo fue lo que, en definitiva, acabó con la agresividad de las vigorosas comunidades montañesas. 


\section{Conclusiones}

Los conflictos que entre los siglos XII y XIII afectaron a amplios sectores del alto Pirineo catalán, enfrentando a buena parte de la nobleza articulada en torno a los vizcondes de Castellbò y a sus aliados y sucesores los condes de Foix, con la Iglesia de Urgel, apoyada esta última por los condes urgelenses y la propia monarquía, se caracterizaron por la acción de unas tropas que aportaron un sesgo específico de violencia y destrucción hasta entonces poco habituales en esas tierras, y que fueron condenadas por ello en repetidas ocasiones, especialmente por la Iglesia de Urgel.

Lejos de tratarse de contingentes foráneos, según podría desprenderse de la terminología empleada en su condena, que los identificaba con aragoneses, brabanzones o «ruptiarii», la documentación refleja el carácter autóctono de sus efectivos, formados por hombres armados de las comunidades montañesas de los altos valles pirenaicos como Andorra, Sant Joan, Cabó y otros de los condados de Urgel y de Cerdaña. Se trata de territorios relativamente periféricos en relación a los principales centros de poder de la zona, cuyas comunidades todavía se hallaban poco integradas en el marco coercitivo del feudalismo. Articulados en huestes que remitían a las formas organizativas del mundo prefeudal, los hombres armados de dichas comunidades habían colaborado históricamente con los poderes de vocación pública, especialmente los obispos y los condes de Urgel, en la defensa y el mantenimiento de la paz pública.

A partir de mediados del siglo XII, el auge de los conflictos internos por la redistribución de rentas en la cúpula de la sociedad local, que derivaría en un conflicto de largo alcance entre los principales linajes de la nobleza laica y la Iglesia de Urgel y sus aliados, acabó desvirtuando el carácter público de las prestaciones militares de dichas comunidades montañesas. De este modo, en el marco de una sociedad fragmentada por las guerras, los principales actores del conflicto se aprovecharon, alternativamente, de las valoradas cualidades militares de dichas tropas, privatizando su servicio y cayendo con ello en una dinámica plenamente feudal. Por su parte, la ampliación del marco impositivo de la Iglesia de Urgel sobre las comunidades rurales, aplicando el discurso de la reforma gregoriana al contexto local de redistribución de las rentas, favoreció su desafección hacia la Iglesia, fomentando actitudes anticlericales que acentuaron la fragmentación de lealtades y la animosidad proyectada sobre los bienes y los hombres de la Iglesia, aportando todo ello, a su vez, argumentos a la Iglesia para condenar la acción de dichos hombres armados. 
Las cualidades militares de dichos contingentes fueron valoradas y temidas a la vez. Se trataba de tropas de a pie, muy aptas en la captura y la destrucción de fortalezas, cuya acción impulsó una sistemática fortificación del alto condado de Urgel y del condado de Cerdaña, con fuertes repercusiones en la articulación territorial de dichos ámbitos. Asimismo, sus asaltos y agresiones continuas contra los intereses de la Iglesia de Urgel también tuvieron graves implicaciones económicas, reflejadas en la caída de su capacidad financiera que repercutió, entre muchos otros aspectos, en la interrupción de las obras de la catedral de Urgel.

La acción de dichos contingentes armados y sus efectos más destructivos se documentan entre 1180 y 1240 aproximadamente, si bien se detectan ya ciertas expresiones de malestar a partir de la década de 1160. La suspensión de las hostilidades por parte de Roger Bernat II de Foix contra el conde Nuño Sancho de Cerdaña y el obispo de Urgel en torno a esa última fecha marcaron el final de las grandes campañas de los contingentes armados montañeses. El incremento de la capacidad coercitiva sobre dichas comunidades por parte de los señores feudales, incluyendo a la Iglesia de Urgel en esta consideración, y la mayor presencia de grandes contingentes foráneos como resultado de la integración de dichos territorios en esferas de acción política cada vez más amplias y eficaces, supusieron el desvanecimiento de estas tropas dentro de los campos de batalla de la región.

\section{Referencias bibliográficas}

Alvira CABrer, Martín (2002), El Jueves de Muret. Barcelona, Universidad de Barcelona.

Alvira Cabrer, Martín (2010), Pedro el Católico, Rey de Aragón y Conde de Barcelona (1196-1213). Documentos, testimonios y memoria histórica. Zaragoza, Institución Fernando El Católico, 6 vols.

Alvira CABrer, Martín y SMITH, Damian (2006-2007), «Política antiherética en la Corona de Aragón: una carta inédita de Inocencio III a la reina Sancha (1203)», Acta Historica et Archaeologica Mediaevalia, 27-28: 65-88.

ArbuÉs GARCIA, Clara y GASCÓn CHOPO, Carles (2017), «Mossèn Pere Pujol i Tubau (1887-1962), arxiver capitular d'Urgell.» En Marc Sureda y Alberto Velasco, ed., Capellans erudits. Eclesiàstics al capdavant de l'acció patrimonial, museística i de recerca historicoartística a Catalunya al segle XX. Solsona, Museu Diocesà i Comarcal de Solsona: 171-189.

BACHRACH, Bernard S. y BACHRACH, David S. (2017), Warfare in Medieval Europe, c. 400-c. 1453. London \& New York, Routledge. 
BAiges I JARDí, Ignasi J.; GASCÓn CHOPO, Carles (2019), Consell de la Terra. Els orígens. Andorra la Vella, Consell General del Principat d'Andorra.

BARAUT I OBIOLS, Cebrià (1988-1989), «Els documents, dels anys 1101-1150, de l'Arxiu Capitular de la Seu d'Urgell», Urgellia, 9: 7-312.

BARAUT I OBIOLS, Cebrià (1990-1991), «Els documents, dels anys 1151-1190, de l'Arxiu Capitular de la Seu d'Urgell», Urgellia, 9: 7-625.

BARAUT I OBIOLS, Cebrià (1992-1993), «Els documents, dels anys 1191-1200, de l'Arxiu Capitular de la Seu d'Urgell», Urgellia, 11: 7-160.

BARAUT I OBIOLS, Cebrià (1994-1995), «La presència i la repressió del catarisme al bisbat d'Urgell (segles XII-XIII)», Urgellia, 12: 487-524.

BARAut I OBIOLS, Cebrià (2005), Cartulari de la vall d'Andorra. Segles IX-XIII, Andorra: Arxiu Nacional d'Andorra, segunda edición.

BAudon DE Mony, Charles (1896), Relations politiques des comtes de Foix avec la Catalogne jusqu'au commencement du XIV siècle. Paris, Alphonse Picard et fils, libraires-éditeurs. 2 vols.

Benito i Monclús, Pere (2005), «La submissió del comte Hug IV d'Empúries i de la noblesa emporitana a l'Església de Girona (1226-1229): una repercussió de la croada albigesa liderada per Lluís VIII, rei de França, a Catalunya.» En Lourdes Plans i Campderrós, dir., Església, societat i poder a les terres de parla catalana. Valls, Cossetània Edicions: 139-154.

Bisson, Thomas N. (1991), «The War of the Two Arnaus: a memorial of the Broken Peace in Cerdanya (1188).» En Miscel-lània en homenatge al P. Agustí Altisent. Tarragona, Diputació de Tarragona: 95-107.

BISSON, Thomas N. (2002), L'impuls de Catalunya. L'època dels primers comtes-reis. Vic, Eumo Editorial ( $2^{\mathrm{a}}$ edición).

BOUSSARD, Jacques (1946), «Les mercenaires au XII ${ }^{\mathrm{e}}$ siècle. Henri II Plantagenet et les origines de l'armée de métier», Bibliothèque de l'École des Chartes, 106/2: 189-224.

DeLCOR, Mathias (1979-1980), «La société cathare en Cerdagne: nobles et bergers du XIIe au XIVe siècle», Bulletin de Littérature Ecclésiastique, 4: 279-304 y 5: 17-49.

Devic, Claude; VAISSETE, Joseph (1879-1905), Histoire Générale du Languedoc. Toulouse, Édouard Privat, Libraire-Éditeur, 16 vols.

DuBY, Georges (1996), «Le dimanche de Bouvines.» En Féodalité. París, Gallimard: 827-1050.

DuVERnOY, Jean (1998), Le dossier de Montségur. Interrogatoires d'Inquisition, 1242-1247. Édition latine. Toulouse, Pérégrinateur Éditeur.

GASCÓN CHOPO, Carles (2010a), «L'irruption des comtes de Foix sur le versant méridional à la fin du XIIe siècle, ses possibles motivations et ses conséquences.» En Claudine Pailhès, dir., 1209-1309. Un siècle intense au pied des Pyrénées. Foix, Conseil Général de l'Ariège-Archives Départementales: 23-40.

GASCÓN CHOPO, Carles (2010b), «Els càtars a la Cerdanya. Invasors o dissidents?», Ker, 4: 19-23. 
GASCÓN CHOPO, Carles (2015), La disidencia cátara y sus bases sociales en la Cataluña de los siglos XII-XIV. Tesis doctoral inédita. Madrid, UNED.

GASCÓn CHOPO, Carles (2017), «Els Foix-Castellbò i el saqueig de la Cerdanya segons dos memorials de greuges del segle XIII», Era. Revista cerdana de recerca, 2: 77-93.

GASCÓN CHOPO, Carles (2018), «Guerra i encastellament a la plana de l’Urgellet (segles XII-XIII)», Butlletí de la Societat Catalana d'Estudis Històrics, 29: 295-236.

GASCÓN CHOPO, Carles (2019), «Dels Dacònides als Montferrer. Història d'un llinatge intervingut per l'Església d'Urgell (segles X-XII).» En Almudena Blasco y Oliver Vergés, eds., Estudis sobre els orígens de la noblesa medieval al nord-est peninsular (segles X-XII). Encamp, Anem Editors: 53-84.

Gonzalvo i Bou, Gener (1994), Les constitucions de Pau i Treva de Catalunya. Barcelona, Generalitat de Catalunya, Departament de Justícia.

GonZalvo I Bou, Gener (1995), «El comtat d'Urgell i la pau i treva.» En El Comtat d'Urgell. Lleida, Universitat de Lleida, Institut d'Estudis Ilderdencs: 71-88.

LINEHAN, Peter (1972-1973), «La carrera del obispo Abril de Urgel: la Iglesia española en el siglo XIII», Anuario de Estudios Medievales, 8: 143-197.

MALlett, Michael (2005), «Mercenarios.» En Maurice Keen, ed., Historia de la guerra en la Edad Media. Boadilla del Monte, Antonio Machado Libros: 269-294.

MANSI, Giovanni Domenico (1778), Sacrorum conciliorum nova et amplissima collectio. T. 22. Venecia, Antonium Zatta. Disponible en red.

MARQUÈS I SALA, Benigne (2006-2008), «Els documents del fons Caboet-Castellbò de l'Arxiu Capitular d'Urgell (1095-1251)», Quaderns d'estudis andorrans, 8: 11-76.

MARQUÈS I SALA, Benigne (2015-2018), «Catàleg dels documents de l'Arxiu Capitular d'Urgell, 1201-1215», Urgellia, 19: 221-331.

Migne, Jacques Paul (1855), Patrologiae cursus completus, vol. 214. París, J. P. Migne Editorem. Disponible en red.

MIRET I SANS, Joaquim (1900), Investigación histórica sobre el vizcondado de Castellbó. Barcelona, Imprenta «La Catalana» de J. Puigventós.

MONFAR Y SORS, Diego (1853), Historia de los condes de Urgel. Barcelona, Establecimiento litográfico y tipográfico de J. E. Montfort. 2 vols.

Puig I CAdAfalch, Josep (1918), Santa Maria de la Seu d'Urgell. Barcelona, Tallers d'arts gràfiques Henrich i C. ${ }^{\text {a }}$

REUTER, Timothy (2005), «La guerra carolingia y otoniana.» En Maurice Keen, ed., Historia de la guerra en la Edad Media. Boadilla del Monte, Antonio Machado Libros: 29-56.

ROVIRA I SOLÀ, Manuel (2005), «La carta de poblament i franquesa de Puigcerdà de 1178», Acta historica et archaeologica mediaevalia, 26: 199-204.

SABATÉ I CURULL, Flocel (1995), «Organització administrativa i territorial del comtat d'Urgell.» En El Comtat d'Urgell. Lleida, Universitat de Lleida, Institut d'Estudis Ilderdencs: 17-70. 
SABATÉ I CuRULl, Flocel (2004), «Catalunya medieval.» En Albert Balcells, dir., Història de Catalunya. Barcelona, L'Esfera dels llibres: 99-334.

SABATÉ I CURULl, Flocel (2007), La feudalización de la sociedad catalana. Granada, Universidad de Granada.

VAuX DE CERnay, Pierre des (1615), Historia Albigensium. Troyes, Jean Griffard et Noël Moreau Imprimeurs. Disponible en red.

VIADER, Roland (2003), L'Andorre du IXe au XIV siècle. Toulouse, Presses Universitaires du Mirail.

Villanueva y Astengo, Jaime (1850), Viage literario a las iglesias de España. T. XI. Madrid, Real Academia de la Historia. 
